\title{
Research on the Solar Distributed PV's Impacts on the Voltage of Distribution Network
}

\author{
Yongsen Wei, Li Li*, and Yan Liu \\ Physics and Engineering Technology Department, Guilin Normal College, Guilin, 541000, China \\ ${ }^{*}$ corresponding author
}

Keywords: photovoltaic generation, distributed network, voltage difference.

\begin{abstract}
The photovoltaic power is gaining momentum and developing fastest among the distributed power generation technologies. The distributed photovoltaic power is connected to the distribution grid through the inverter. And it is stochastic and different from the traditional power plants. So it is necessary to study the impact of distributed photovoltaic power on the distribution grid. This paper introduces solar energy and distributed power generation. From the viewpoint of voltage drop in power network, the voltage variation mechanism of distribution network before and after the connection of photovoltaic (PV) generation to distribution network is researched. And the conclusion is that connecting PV generation to distribution network makes line voltage of distribution network arisen.
\end{abstract}

\section{Introduction}

Solar energy is the most important basic energy in a variety of renewable energies[1]. It is widely distributed and easily accessible. The number of energy which solar radiates to the Earth's land surface is about 17 trillion kilowatts a year. Solar energy resources and distribution in various regions is shown in Table 1. Researches and Practice have shown that distributed power generation will play an increasingly important role in the sustainable development process. Distributed power generation helps to make full use of abundant clean and renewable energy around and provide “Green Power”for users[2-4].

Table 1:Solar energy resources and distribution in various regions

\begin{tabular}{|c|c|c|c|}
\hline type & region & $\begin{array}{l}\text { annual sunshine } \\
\text { hour }\end{array}$ & $\begin{array}{l}\text { total annual } \\
\text { radiation }\end{array}$ \\
\hline first & $\begin{array}{c}\text { western Tibet,southeastern Xinjiang,western } \\
\text { Qinghai,western Gansu } \\
\text { southeastern Tibet,southern Xinjiang,eastern }\end{array}$ & $2800-3300$ & $160-200$ \\
\hline second & $\begin{array}{l}\text { Qinghai,southern Ningxia,central Gansu,Inner } \\
\text { Mongolia,northern Shanxi,northwestern Hebei } \\
\text { northern Xinjiang,southeastern Gansu,southern } \\
\text { Shanxi,northern Shaanxi,southeastern }\end{array}$ & $3000-3200$ & $140-160$ \\
\hline third & $\begin{array}{l}\text { Hebei,Shandong,Henan,Jilin, Liaoning and } \\
\text { Yunnan,southern Guangdong,southern }\end{array}$ & $2200-3000$ & $120-140$ \\
\hline fourth & $\begin{array}{l}\text { Fujian,northern Jiangsu,northern Anhui } \\
\text { Hunan,Guangxi,Jiangxi,Zhejiang,Hubei,northern } \\
\text { Fujian,northern Guangdong,southern } \\
\text { Shanxi,southern Jiangsu,southern } \\
\text { Anhui,Heilongjiang }\end{array}$ & $1400-2200$ & $100-120$ \\
\hline fifth & Sichuan,Guizhou & $1000-1400$ & $80-100$ \\
\hline
\end{tabular}

In first,second and third areas,annual sunshine hour is more than 2000 hour. solar energy of the three areas is rich. And its area is very large. They are accounting for about two-thirds of the country total area. They have good conditions for the use of solar energy. Solar energy condition of the fourth and fifth areas is poor ,but there are still some value[5-7]. 


\section{Distributed power generation}

Distributed generation refers to the clean and green power generation facility can generate power economicly, efficiently and reliably with features as follows[8-10]: power in the range of tens of kilowatts to tens of megawatts, modular and near the load. Distributed generation is different from the traditional centralized power generation,long-distance transmission and large internetwork power generation form. Distributed power can be seen as a controllable dynamic load from the perspective of system. Taking special needs of the respective heat load and environmental protection and economic requirements into consideration,distributed power generation needs to run at rated conditions. It has a lot of advantages such as near the users,flexible configuration,reducing network loss,improving reliability and so on. Due to these advantages,it has high economic and social benefits. Therefore,Finance Ministry and other departments jointly issue "Golden Sun"project policy in 2009. The policy is aimed at promoting domestic distributed photovoltaic application.

Distributed generation includes off-grid PV system which is shown in Fig. 1 and grid distributed photovoltaic power generation system which is shown in Fig. 2.

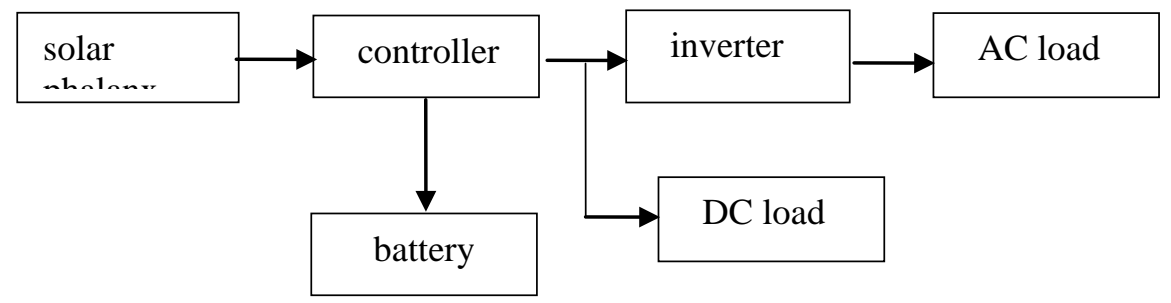

Fig. 1:off-grid PV system fundamental

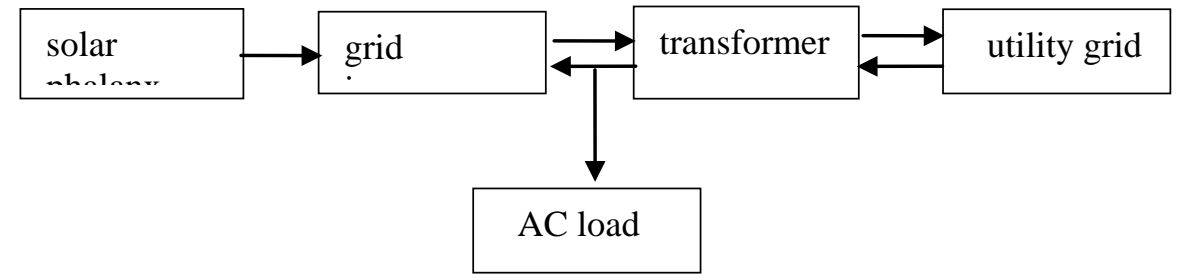

Fig. 2:grid PV system fundamental

After PV's access to distribution network,fundamental changes in the power distribution system have occurred:it changes into a active network with SME power from a radial passive network. Due to output power of PV has features such as intermittent and volatility and so on,the control and management of distribution system becomes more complex. Its main effects are as follows:(1)the planning and operation of distribution network such as reactive power compensation,voltage control and protection will completely change. (2)distribution automation system and content and methods of demand-side management also need to be reconsidered. (3)the control and scheduling of distributed power such as PV must be coordinated. . (4)laws,regulations and industry standards about distributed power such as PV need to develop properly. Therefore,researching on distribution automation system with distributed power such as PV has become one key of power scientific research[11-13].

\section{PV's impact on the voltage of distribution grid}

Photovoltaic power generation and distributed power generation system below the rank of MW are susceptible to the impact of factors such as large load attack in independent runtime due to small capacity and relatively simple load regulation mean. And it results in low quality of power supply. Therefore,the best mode of operation should be operated with the local power grid. And network issue is a critical issue that plagues many small capacity distributed generation. And network issue generally face difficulties. 
The following analyzes impact of single photovoltaic access to network on the distribution grid voltage. There are $\mathrm{N}$ users on line. Apparent power of the user is $P_{n}+j Q_{n}(n=1,2, \cdots, N)$. Where, the unit of $P_{n}$ is MW. Line initial terminal voltage is $U_{0}$ and assuming it remains unchanged. The voltage of the $\mathrm{n}$ user on line is $U_{n}(n=1,2, \cdots, N)$. Line impedance between the $n-1$ user and the n user is $R_{n}+j X_{n}=l_{n}(r+j x)$. Where, $l_{n}$ is line length between the $\mathrm{n}-1$ user and the $\mathrm{n}$ user; $\mathrm{r}$ and $\mathrm{x}$ are resistance and reactance of unit line length; The building photovoltaic capacity of the access of the p user is $P_{v}$.

i)Before the access of photovoltaic. Assuming the direction which active and reactive power flow to the load is positive;Otherwise it is negative. The drop between the $m$ user and the $m-1$ user is

$$
\Delta U_{m}=U_{m}-U_{m-1}=-\frac{\sum_{n=m}^{N} P_{n} R_{m}+\sum_{n=m}^{N} Q_{n} X_{m}}{U_{m-1}}=-\frac{\sum_{n=m}^{N} P_{n} r l_{m}+\sum_{n=m}^{N} Q_{n} X l_{m}}{U_{m-1}}
$$

The voltage of the $m$ user is $U_{m}$.

$$
U_{m}=U_{0}+\sum_{k=1}^{m} \Delta U_{k}=U_{0}-\sum_{k=1}^{m} \frac{\sum_{n=k}^{N} P_{n} r l_{k}+\sum_{n=k}^{N} Q_{n} x l_{k}}{U_{k-1}}
$$

ii)After the access of photovoltaic. The voltage of the $m$ user is $U_{m}$.

$$
U_{m}=U_{0}-\sum_{k=1}^{m} \frac{\left(\sum_{n=k}^{N} P_{n}-P_{v}\right) r l_{k}}{U_{k-1}} \succ V_{0}-\sum_{k=1}^{m} \frac{\sum_{n=k}^{N} P_{n} r \boldsymbol{l}_{k}}{U_{k-1}}
$$

Equation (4) shows that the access of photovoltaic can increase line voltage. The voltage difference between the $m$ user and the $m-1$ user is

$$
U_{m}-U_{m-1}=-\frac{\left(\sum_{n=m}^{N} P_{n}-P_{v}\right) r l_{m}}{U_{m-1}}
$$

The voltage of the user that is located in photovoltaic access point is

$$
\begin{aligned}
& U_{m}=U_{0}-\sum_{k=1}^{p} \frac{\left(\sum_{n=k}^{N} P_{n}-P_{v}\right) r l_{k}}{U_{k-1}}-\sum_{k=p+1}^{m} \frac{\sum_{n=k}^{N} P_{n} r \boldsymbol{l}_{k}}{U_{k-1}} \\
& U_{m}-U_{m-1}=\sum_{k=p+1}^{m-1} \frac{\sum_{n=k}^{N} P_{n} r l_{k}}{U_{k-1}}-\sum_{k=p+1}^{m} \frac{\sum_{n=k}^{N} P_{n} r l_{k}}{U_{k-1}}=-\frac{\sum_{n=m}^{N} P_{n} r l_{k}}{U_{k-1}} \prec 0
\end{aligned}
$$

Equation (6) shows that voltage of $m$ point is always lower than $m-1$ point.

\section{Summary}

Distributed generation technology is a new generation of power generation technology. Its development rise momentum is unstoppable. The design,planning, operation and control of distribution network should be upgraded to accommodate the development of distributed generation. The photovoltaic power is gaining momentum and developing fastest among the distributed power generation technologies. There will have more and more distributed photovoltaic power access to distribution network. So it is necessary to study the impact of distributed photovoltaic power on 
the distribution grid. By researching on spotting voltage changes in front and rear of photovoltaic access to distribution network from the perspective of the grid voltage drop and analyzing impact of single photovoltaic access to network on the distribution grid voltage, we can conclude that the line voltage will increase after the intervention of PV. Assuming the initial terminal voltage of line is constant and single photovoltaic access to network,line voltage has followed variation trend with the gradual increase of the photovoltaic output:(1)it will reduce gradually;(2)it will decline first,and then raise,and finally reduce;(3)it will raise first and reduce later.

\section{Acknowledgements}

This paper is supported by the phased research results of 2014 Guangxi higher education teaching reform project (2014JGA291), higher vocational education"Fusion Engineering Research"develop and industry abutment electronic information technology talents's research and practice

\section{References}

[1]Conti S,Raiti S,Tina G. Small-scale Embedded Generation Effect on Voltage Profile:An Analytical Method. IEEE Proceedings-Generation Transmission and Distribution,2003,150(1):78-86.

[2]Kim T E,Kim J E. Considerations for the Feasible Operating Distribution

System. In:Proceedings of 2002 IEEE Power Engineering Society Summer Meeting,Vol 1,Piscataway(NJ):IEEE,2002,42-48.

[3]Caire R,Retiere N,Martino S,et al. Impact Assessment of LV Distributed Generation on MV Distribution Network. In:Proceedings of 2002 IEEE Power Engineering Society Summer Meeting,Vol 3. Piscataway(NJ):IEEE,2002,1423-1428.

[4]Conti S,Raiti S,Tina G. Small-scale Embedded Generation Effect on Voltage Profile:An Analytical Method. IEEE Proceedings-Generation Transmission and Distribution. 2003,150(1):78-86.

[5]Carie R,Retiere N,Martino S,et al. Impact Assessment of LV Distributed Generation on MV Distributed Network. In:Proceedings of 2002 IEEE Power Engineering Society Summer Meeting,Vol 3. Piscataway(NJ):IEEE,2002. 1423-1428.

[6]Kim T E,Kim J E. Considerations for the Feasible Operation Range of Distributed Generation Interconnected to Power Distribution System. In:Proceedings of 2012 IEEE Power Engineering Society Summer Meeting,Vol 1. Piscataway(NJ):IEEE,2012. 42-48.

[7]Yu Lei,Xu Li-Li,Zhou Xin. Impacts of Distributed PV Power Generation on Distributed and It's Countermeasure[J]. North China Electric Power,2013(10):13-17.

[8]Wang Zhi-Qun,Zhu Shou-Zhen,Zhou Shuang-Xi,et al. Impacts of Distributed Generation on Voltage of Distribution of Electric Power Systems,2013,28(16):56-60.

[9]Chen Hai-Yan,Duan Xian-Zhong,Chen Jin-Fu. Distribution Generation Planning Model and Algorithm Considering Static Voltage Stability Constrain in Distribution Network[J]. Power System Technology,2012,30(21):11-14.

[10]Choi J H,Kim J C. Advanced Voltage Regulation Method of Power Distribution System Interconnected with Dispersed Storage and Generation System[J]. IEEE Trans on Power Delivery,2011,16(2):329-334.

[11]Hu Hua,Wu Shan,Xia Xiang,et al. Computing the Maximum Penetration Level of Multiple Distributed Generations in Distribution Network Taking into Account Voltage Regulation Constraints[J]. Proceedings of the CSEE,2006,26(19):13-17.

[12]Scott N C,Atkinson D J,MORRELL J E. Use of Load Control to Regulate Voltage on Distribution Networks with Embedded Generation[J]. IEEE Trans. on Power Systems,2012,17(2):510-515.

[13]Zhu Y,Tomsovic K. Adaptive Power Flow Method for Distribution Systems with Dispersed Generation. IEEE Trans on Power Delivery,2002,17(2):822-827. 